\title{
EDUTECH
}

\section{PENERAPAN GAMIFIKASI PADA PENILAIAN ABSENSI (PenA) UNTUK MENINGKATKAN MOTIVASI BIMBINGAN}

\section{Oleh :}

Untung Rahardja, Qurotul Aini , Abdul Hayat, Nuke Puji Lestari Santoso

STMIK RAHARJA

Jl. Jendral Sudirman No. 40, Modernland Cikokol, Tangerang 15117, Ph/Fax: 021-5529692

e-mail: untung@raharja.info, aini@raharja.info, abdul.hayat@raharja.info,nuke@raharja.info

\begin{abstract}
Abstrack. Entering the disruptive 4.0 era, information technology is increasingly needed in the education sector. In presenting information, it should be up to date and have a sophisticated information technology breakthrough. At Higher Education there is an online attendance system that is using PenA (Attendance Assessment). However, the process of guidance activities is not yet maximal in the presence of guidance students. There are 2 (two) problems in this study, namely the absence of a system that is able to motivate the presence of student guidance and the results of the guidance time. To solve these 2 (two) problems, the existence of gamification techniques on the Attendance Assessment (PenA) website system in order to increase student motivation in the tutoring activities of the supervisor so that students are more diligent in the presence of guidance. The gamification can be said to be a reward in the Attendance Assessment (PenA) system. From the application of the gamification technique on Attendance Assessment (PenA) 7 research methods were used and 7 (seven) review literature. Attendance Assessment (PenA) now has the advantage of logging in using SSO, and also being absent by scanning Qr Code. With the gamification technique on Attendance Assessment (PenA) it is able to provide a level of motivation for students in their attendance. As well as visible achievements of students in craft attendance in guidance.
\end{abstract}

Informasi Artikel :

Artikel diterima 3 Januari 2019

Perbaikan 25 Januari 2019

Diterbitkan 14 Februari 2019

Terbit Online 15 Febuari 2019

Kata kunci: Gamification, Penilaian Absensi (PenA), Reward, Motivation

\section{A. PENDAhuluan}

Zaman era disruptif 4.0 sudah semestinya internet mampu dapat dimanfaatkan keberadaannya dalam mendapatkan informasi yang tak terbatas [1]. Sehingga menimbulkan perkembangan teknologi yang cepat dan perubahan yang signifikan [2]. Begitu pula dalam proses belajar mengajar perubahan perlu dilakukan guna meningkatkan sebuah kualitas dan informasi yang akurat [3]. Sebagai penunjang motivasi mahasiswa dalam kegiatan bimbingan belajar yang baik diberikan informasi berupa hasil kehadiran mahasiswa setiap bimbingan terhadap dosen bimbingan [4]. Salah satunya dengan sistem Penilaian Absensi

DOI:https://doi.org/10.17509/e.v18i1.14671 
(PenA) yang dilakukan secara online oleh kehadiran mahasiswa bimbingan.

Pada sistem Penilaian Absensi (PenA) sebelumnya kehadiran mahasiswa terjadi begitu saja belum adanya hasil capaian yang berbeda antara mahasiswa yang hadir dalam waktu lama dengan mahasiswa yang hadir dengan waktu lebih sedikit. Selain itu, dari kegiatan bimbingan belajar mengakibatkan kehadiran mahasiswa bimbingan terlihat biasa saja dan kurangnya minat dalam proses bimbingan terhadap dosen pembimbing.

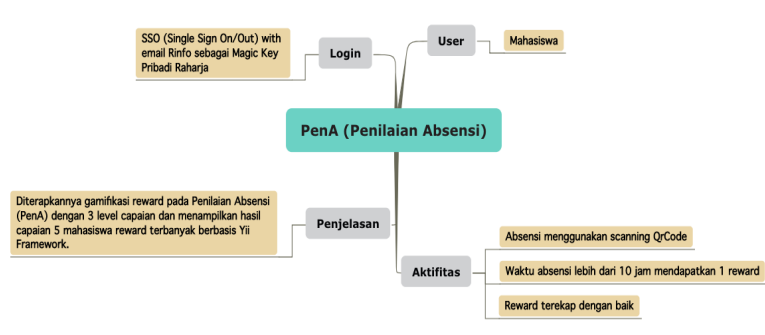

Gambar 1. Mind Mapping Penilaian Absensi (PenA)

Dari permasalahan di atas maka penyelesaiannya dapat dijelaskan dalam mind mapping Penilaian Absensi (PenA) dengan diterapkannya teknik gamifikasi yaitu reward pada Penilaian Absensi (PenA). Mendeskripsikan (1) Sistem Penilaian Absensi (PenA) login menggunakan SSO with Rinfo yang memudahkan mahasiswa dalam absen [5], (2) User artinya Penilaian Absensi (PenA) digunakan oleh mahasiswa bimbingan, (3) Aktivitas pada PenA yaitu adanya sistem reward yang akan didapatkan setelah 10 jam absensi kemudian reward terekap dengan baik, (4) Penjelasan yaitu diterapkannya gamifikasi reward pada Penilaian Absensi (PenA) dengan 3 level capaian dan menampilkan hasil capaian 5 (lima) mahasiswa reward terbanyak berbasis Yii Framework. Dari mind mapping di atas terlihat bahwa dengan adanya penerapan reward pada sistem Penilaian Absensi (PenA) mahasiswa menjadi lebih termotivasi dalam kehadiran bimbingan di Perguruan Tinggi.

Sistem informasi yang berkembang esat dan banyak data-data penting yang srkandung di dalamnya, maka ibutuhkan suatu jaminan keamanan ntuk sistem informasi tersebut bisa terjaga [6]. Pada website Penilaian Absensi (PenA) menggunakan framework Yii dengan konsep MVC yang lazim digunakan oleh framework pada umumnya. MVC merupakan metode pengembangan aplikasi dengan memisahkan data (Model), tampilan (View) dan pengolahannya (Controller). Sehingga dalam membuat pengembangan menjadi lebih efektif dan efisien dikarenakan developer dapat membagi pekerjaan antara tampilan aplikasi dan logika di dalam programnya 
[7].

Sudah banyak penelitian yang sebelumnya dilakukan mengenai pemanfaatan maupun perkembangan teknologi informasi mengenai sistem absensi. Pengembangan sistem absensi ini melakukan tujuh tinjauan pustaka terhadap penelitian terdahulu untuk menjadi pedoman di dalam pengembangan ini, adalah sebagai berikut :

1. Penelitian yang dilakukan oleh Qurotul Aini, dkk dengan judul "PENERAPAN ZPRENEUR DENGAN TEHNIK GAMIFIKASI BERUPA TRANSFER ARMO UNTUK MENINGKATKAN KUALITAS PEMBELAJARAN" membahas digunakannya gamifikasi pada Zpreneur yang berguna meningkatkan mahasiswa/i dalam proses pembelajaran dengan inovasi yang baru dan lebih terpacu juga semangat [8].

2. Penelitian yang dilakukan oleh Dian Pramana dengan judul "IMPLEMENTASI

GAMIFICATION PADA

APLIKASI UJIAN ONLINE

BERBASIS WEBSITE" membahas bahwa gamifikasi diterapkan pada ujian online agar berlangsung dengan lebih menyenangkan, tidak monoton dan praktis dengan berbasis website dan dibangun dengan bahasa pemrograman PHP [9].

3. Penelitian yang dilakukan oleh Dewi Mariana Apriani, dkk dengan judul "Penerapan Gamifikasi Pada Sistem Informasi Penilaian Ujian Mahasiswa Untuk Meningkatkan Kinerja Dosen" dengan adanya gamifikasi pada sistem penilaian PEN+ mampu memotivasi dosen dalam menginput nilai mahasiswa lebih cepat dari waktu due yang di tentukan [10].

4. Penelitian yang dilakukan oleh Kitab Suci, dkk dengan judul "Penerapan iDu iLearning Plus berbasis Gamification Sebagai Media Pembelajaran Jarak Jauh pada Perguruan Tinggi” adanya gamifikasi pada iLearning+ dalam proses pembelajaran mampu mahasiswa menjadi lebih semangat dalam mempelajari materi yang diberikan oleh dosen [11].

5. Penelitian oleh Saiful anwar, dkk dengan judul "EFEKTIFITAS GAMIFICATION BERBASIS BLENDED LEARNING PADA MATA KULIAH PENDIDIKAN EKONOMI" membahas efektifitas penggunaan gamifikasi dalam proses 
pembelajaran mata kuliah

pembaharuan pendidikan ekonomi dimana mahasiswa lebih tertarik pada konsep tersebut [12].

6. Penelitian oleh Supriyanto dengan judul "Perancangan Penerapan Gamifikasi pada Media Informasi Ekowisata" bahwa dengan menggunakan pendekatan gamifikasi pada integrasi media informasi dengan sebuah media sosial dapat meningkatkan partisipasi wisatawan dalam mengisi konten media informasi pengelola ekowisata [13].

7. Penelitian yang dilakukan oleh Dinda ayu Yusia Wastari, dkk dengan judul "PENERAPAN MODEL PEMBELAJARAN KOOPERATIF BERBASIS GAMIFIKASI UNTUK MENINGKATKAN HASIL

BELAJAR MATERI JURNAL PENYESUAIAN PADA SISWA KELAS X AKUNTANSI G SMK MUHAMMADIYAH YOGYAKARTA TAHUN AJARAN 2017/2018” dengan adanya gamifikasi dalam Penerapan Model Pembelajaran Kooperatif berpengaruh dalam meningkatkan hasil belajar Materi Jurnal Penyesuaian pada Siswa Kelas X Akuntansi G [14].
Perlu diperhatikan dalam menyelesaikan suatu masalah salah satunya dengan menggunakan metode penelitian yang tepat sehingga menghasilkan informasi yang akurat [15]. Maka digunakan 7 (tujuh) tahapan dalam penelitian ini, yaitu Rumusan masalah, Rancangan penelitian, Pengumpulan data, Pengolahan data, Penyajian data, Analisa data, Laporan penelitian.

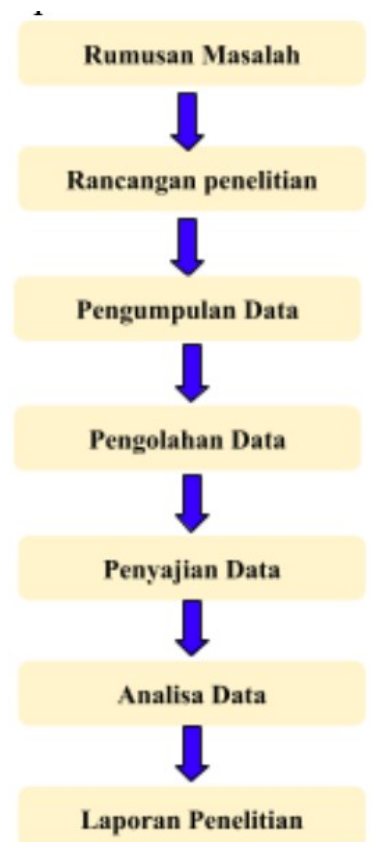

Gambar 2. Metode penelitian

Berikut 7 (tujuh) penjelasan metode penelitian yang digunakan:

1. Rumusan masalah, peneliti melakukan observasi guna mengetahui permasalahan pada sistem kehadiran mahasiswa bimbingan yang terjadi.

DOI:https://doi.org/10.17509/e.v18i1.14671 
2. Rancangan Penelitian yang dilakukan peneliti dalam membuat sebuah prototype guna memudahkan dalam pemahaman rancangan saat diterapkan pada website Penilaian Absensi (PenA).

3. Peneliti mengumpulkan data untuk dimasukkan ke dalam database sistem Penilaian Absensi (PenA) seperti data dosen pembimbing, data mahasiswa bimbingan, serta data ruangan.

4. Data yang sudah didapatkan oleh peneliti kemudian diolah dan integrasikan pada website Penilaian Absensi (PenA) sehingga diterapkan.

5. Penyajian data yang sudah diolah disajikan dalam bentuk informasi berupa menu reward yang berguna bagi mahasiswa bimbingan maupun pembimbing dalam melihat aktifitas kehadiran.

6. Peneliti menganalisa data dari proses awal permasalahan hingga diimplementasikan.

7. Laporan Penelitian yang dilaporkan dengan baik secara keseluruhan hingga permasalahan mampu diselesaikan dengan baik.

\section{B. HASIL DAN PEMBAHASAN}

Bagian ini menjelaskan mengenai analisa kebutuhan dari sistem yang dirancang. Didasari dari analisa yang dihasilkan, kemudian dilanjutkan dengan melakukan perancangan yang terdiri atas rancangan sistem, rancangan basis data serta rancangan user interface. Dan terakhir implementasi sistem serta disajikan berupa screenshoot sistem gamifikasi berupa reward terhadap kehadiran mahasiswa dalam bimbingan belajar.

1. Analisa Permasalahan

Penilaian Absensi (PenA) merupakan sistem kehadiran secara online bagi mahasiswa bimbingan pada Perguruan Tinggi Raharja [16]. Dengan adanya sistem Penilaian Absensi (PenA) dosen pembimbing mampu memonitoring kehadiran mahasiswa bimbingan secara online jika terhubung dengan koneksi. Sehingga kehadiran yang paling tinggi mampu menjadi tolak ukur penilaian lebih bagi mahasiswa bimbingan terhadap dosen pembimbing yang menjadi gaya kepemimpinan, motivasi maupun performa pada Perguruan Tinggi [17]. Selain itu, terlihat juga mahasiswa yang kurang rajin dalam kehadiran bimbingan. Sehingga menjadi faktor bagi dosen pembimbing dalam menilai mahasiswa tersebut.

Namun timbulnya permasalahan pada sistem Penilaian Absensi (PenA) adalah belum adanya sistem yang mampu memotivasi mahasiswa dalam 
bimbingan sehingga kurangnya waktu bimbingan yang dilakukan oleh mahasiswa. Selain itu hasil capaian waktu bimbingan pun belum dirangkum dengan baik pada website Penilaian Absensi (PenA).

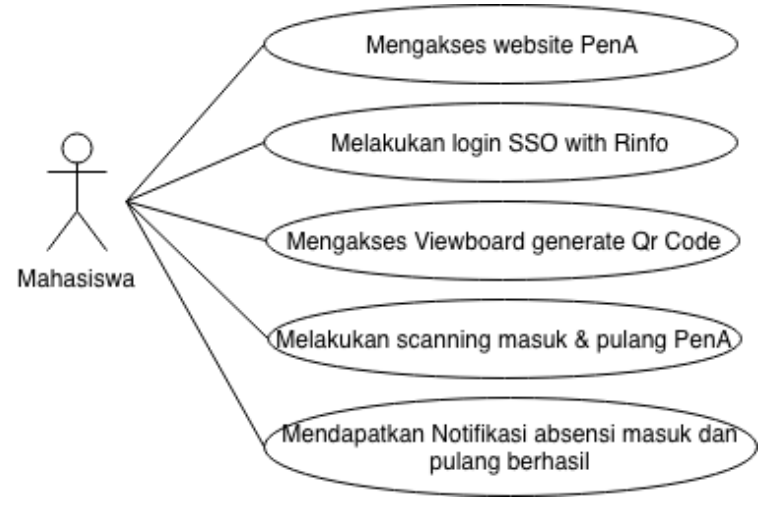

Gambar 3. Use case diagram Penilaian Absensi (PenA) yang berjalan

Dari gambar use case diagram diatas merupakan alur kehadiran mahasiswa secara online menggunakan website Penilaian Absensi (PenA). Adapun dari gambar alur di atas terdapat 1 (satu) aktor yaitu mahasiswa bimbingan yang menggunakan sistem Penilaian Absensi (PenA) secara online. Dan 5 (lima) aktivitas sistem Penilaian Absensi (PenA) yang berjalan dimulai dengan mengakses website Penilaian Absensi (PenA) untuk melakukan absensi kehadiran hingga mendapatkan email notifikasi telah berhasilnya melakukan scanning.

No. SK Akreditasi Ristekdikti : 34/E/KPT/2018
2. Integrasi tabel Master

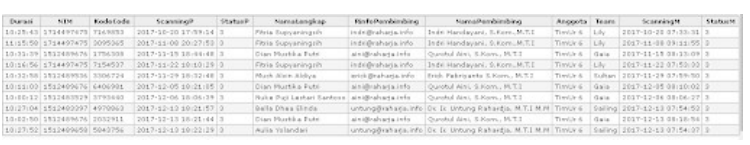

Gambar 4. Tabel Master PenA

Dengan adanya integrasi pada Gambar tabel master ini yang berisikan nama mahasiswa, Nim, durasi, unik ID, Nama pembimbing, anggota, Team, waktu scanning masuk dan waktu scanning keluar. Berfungsi agar ketika mahasiswa melakukan scanning QrCode kehadiran dengan durasi yang sudah ditentukan maka akan muncul reward yang didapatkan oleh mahasiswa tersebut.

\section{Pemecahan Masalah}

Penjelasan permasalahan yang tertera di atas sudah dilakukannya kehadiran secara online yaitu dengan scanning QrCode guna memperlancar proses presensi mahasiswa, namun belum adanya sistem yang mampu memotivasi kehadiran mahasiswa. Guna mengatasi hal tersebut maka ditambahkan sistem gamifikasi pada sistem Penilaian Absensi (PenA) untuk meningkatkan motivasi kehadiran mahasiswa bimbingan di kampus.

Dengan adanya kehadiran total waktu 10 jam mahasiswa bimbingan akan mendapatkan 1 (Satu) reward dalam hitungan 1 hari. Reward tersebut sebagai DOI:https://doi.org/10.17509/e.v18i1.14671 
bentuk apresiasi kehadiran mahasiswa bimbingan yang sudah rajin atau semangat dalam bimbingan.

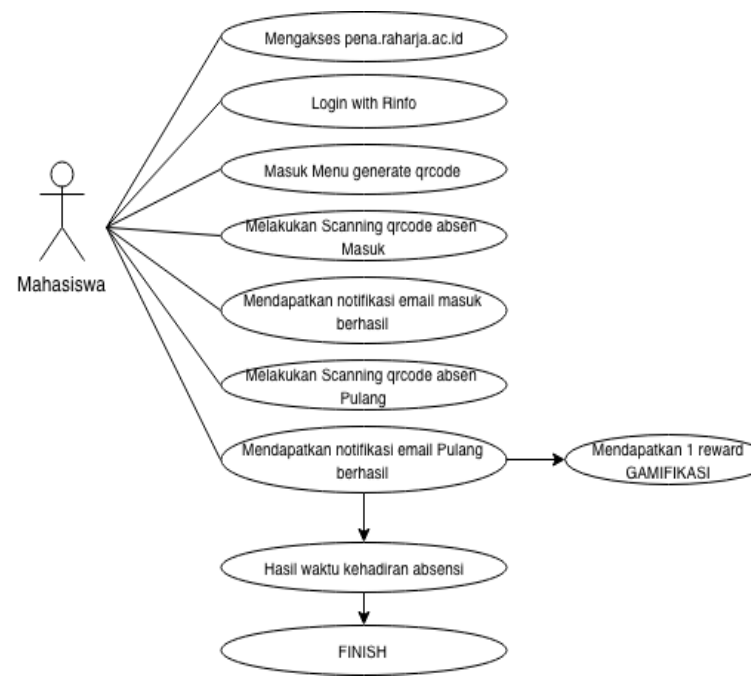

Gambar 5. Use Case diagram alur reward $\mathrm{PenA}$

Dari gambar 5 terdapat 1 (satu) aktor yaitu mahasiswa yang melakukan absensi pada website Penilaian Absensi (PenA) dengan menggunakan scanning QrCode. Setelah berhasil melakukan absen, akan mendapatkan email notifikasi absen masuk dan pulang. Jika sudah memenuhi syarat yaitu total kehadiran waktu absensi selama 10 (sepuluh) jam maka mahasiswa bimbingan berhak mendapatkan 1 (satu) reward secara otomatis. Sehingga bentuk reward atau gamifikasi tersebut mampu memotivasi mahasiswa bimbingan.

4. Listing Program

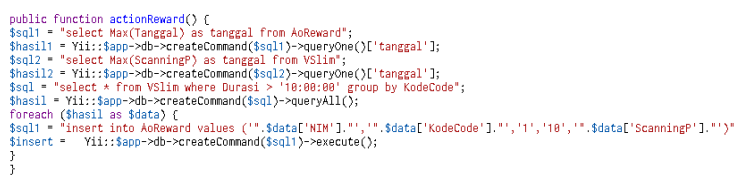

Gambar 6. Update berdasarkan durasi kehadiran mahasiswa

Pada gambar 6 mahasiswa bimbingan yang sudah mencapai waktu 10 jam secara otomatis mendapatkan 1 (satu) reward. Kemudian sistem Penilaian Absensi (PenA) sudah mampu update secara otomatis total keseluruhan kehadiran mahasiswa pada jam 21.00 WIB tanpa harus admin klik lagi. Yaitu menggunakan cron job yang berguna untuk mengeksekusi fungsi yang sebelumnya dibuat secara otomatis [18]. Cron job adalah sistem penjadwalan secara otomatis yang dibuat menggunakan command program [19].

Adanya integrasi dengan tabel reward dengan function reward untuk mendapatkan data mahasiswa secara lebih objektif dengan total durasi lebih dari 10 jam.

Gambar 7. Menampilkan data pada Menu Reward

Pada Gambar 7. merupakan query yang digunakan untuk menampilkan data secara keseluruhan dengan tipe data yaitu Array pada website Penilaian Absensi (PenA).

DOI:https://doi.org/10.17509/e.v18i1.14671 


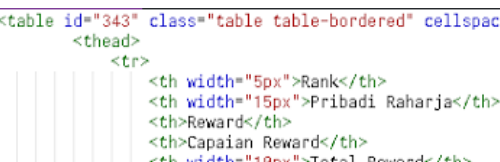

Gambar 8. Field pada tabel menu

\section{Reward}

Gambar 8 digunakan untuk menampilkan field pada tabel yang ada di website Penilaian Absensi (PenA).

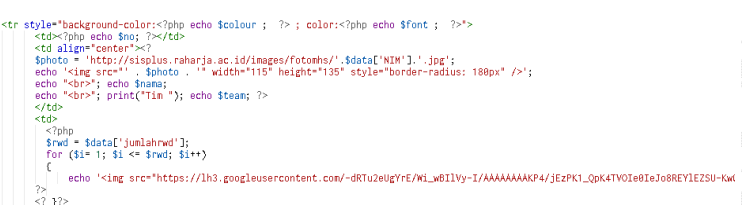

Gambar 9. Script tampilan foto dan lambang reward

Gambar 9. menampilkan foto mahasiswa bimbingan pada halaman menu Reward Penilaian Absensi (PenA) dan juga lambang reward yang didapatkan. Adanya integrasi foto tabel reward dengan sisplus agar memudahkan sebagai identitas mahasiswa bimbingan [20].

Gambar 10. Lambang reward PenA

Pada gambar 10 merupakan script untuk menampilkan lambang reward Penilaian Absensi (PenA) sesuai kategori yang didapatkan.

No. SK Akreditasi Ristekdikti : 34/E/KPT/2018
5. Implementasi

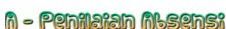
kinnto

\section{INFORMATION PENA}
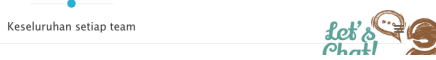

Gambar 11. Tampilan Home PenA

Menu Utama website Penilaian Absensi (PenA) yaitu http:// pena.raharja.ac.id/ yang dapat diakses oleh mahasiswa bimbingan. Mahasiswa bimbingan dapat Login dengan mudah yaitu menggunakan SSO (Single Sign On) .

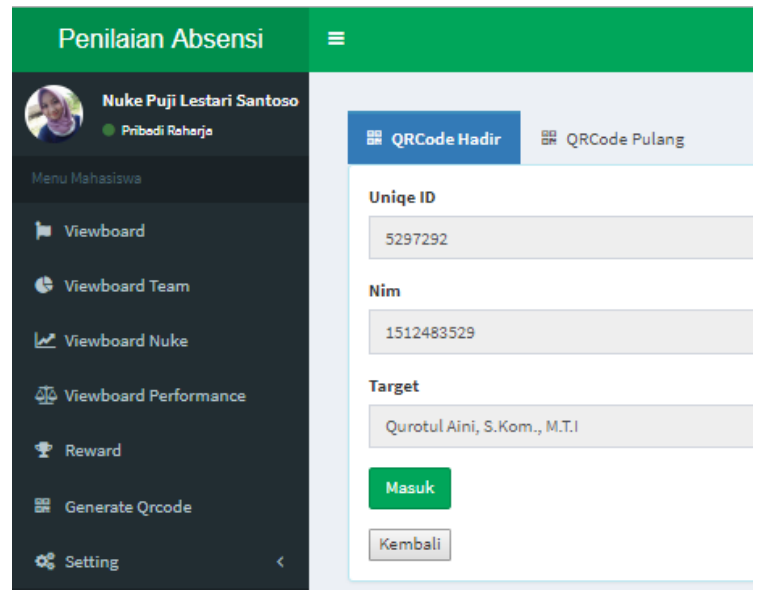

Gambar 12. Menu Generate QrCode

Pada gambar 12 menjelaskan bahwa mahasiswa bimbingan untuk melakukan kehadiran pada sistem Penilaian Absensi (PenA) harus melakukan generate 
QrCode Hadir secara online. Dengan adanya informasi kode unik ID, Nim, dan Dosen pembimbing. Kemudian adanya QrCode Pulang untuk mahasiswa melakukan generate berakhirnya kehadiran bimbingan sehingga terekam dengan baik durasi bimbingan hari ini.

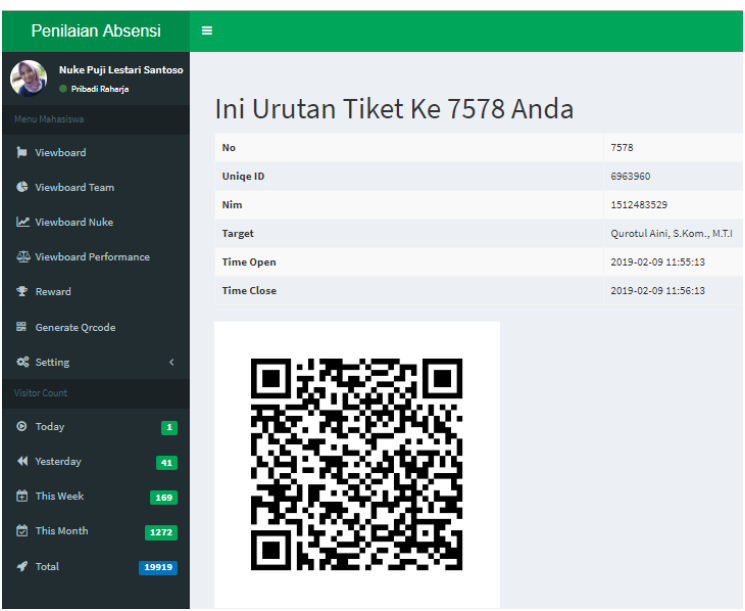

Gambar 13. Gener ate QrCode Hadir dan Pulang

Gambar 13 ini menandakan bahwa mahasiswa bimbingan dapat melakukan kehadiran dengan scanning QrCode yang sudah tergenerate. Adanya unik id, Nim, Dosen Pembimbing serta waktu berakhirnya QrCode tersebut sebagai informasi bagi mahasiswa bimbingan. Begitu pula dengan akhir dari bimbingan juga melakukan generate QrCode Pulang. Dimana dari generate kehadiran dan pulang akan terlihat durasi total kehadiran pada email.

No. SK Akreditasi Ristekdikti : 34/E/KPT/2018

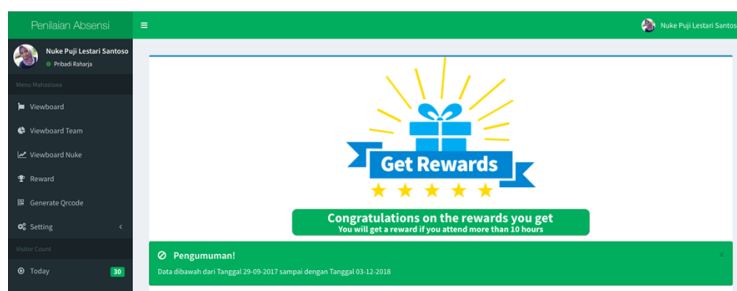

Gambar 14. Tampilan Menu Reward

Gambar 14 merupakan Halaman menu Reward yang mana menampilkan keseluruhan hasil reward yang didapatkan mahasiswa bimbingan dan sudah ter-rekap dengan baik dalam tabel.

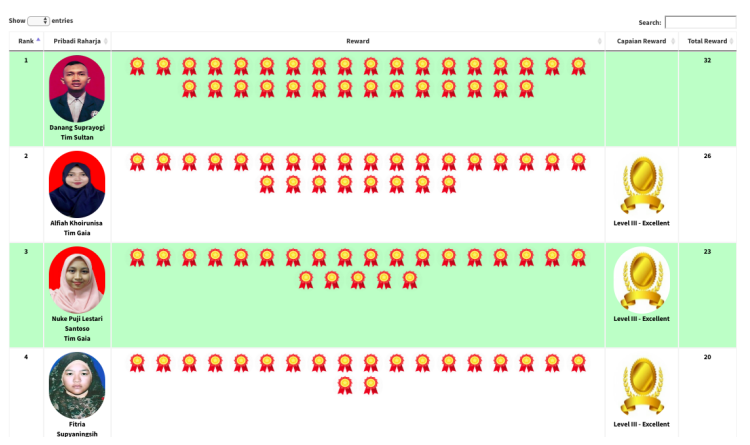

Gambar 15. Tampilan mahasiswa mendapatkan reward

Pada gambar 15 merupakan tampilan website menu reward Penilaian Absensi (PenA) dimana terlihat nama mahasiswa, lambang Reward, total reward. Mahasiswa bimbingan yang sudah memasuki waktu durasi 10 jam akan mendapatkan 1 (satu) reward.

Gambar 16. Level reward PenA DOI:https://doi.org/10.17509/e.v18i1.14671 
Pada gambar 16 Terdapat 3 (tiga) tingkatan level reward website Penilaian Absensi (PenA), dimana memiliki kriteria yang berbeda-beda. Level I jika mendapatkan 1-5 reward dinamakan Level I-Good. Level II jika mendapatkan 6-15 reward dinamakan Level II - Very Good. Level III jika mendapatkan 16 30 reward dinamakan Level III Excellent. Penyajian informasi sangat akurat guna mengukur aktivitas keaktifan mahasiswa [21]. Menjadi suatu teknologi informasi sebagai pendukung strategi yang terintegrasi [22]. Dan dengan didukung gamifikasi pada ilearning education dapat terus termotivasi [23].

PenA - Penilaian Absensi
Notifikasi PenA
Dear Pribadi Raharja,
Congratulations, Nuke Puji Lestari santoso sudah melakukan scanning
pulang pada Ruangan rec@raharja.info tepat pukul 30.11-2018 19:06:46
dengan Pembimbing Qurotul Aini, S.Kom., M.T.I durasi bimbingan selama
10:43:05.
Have a Great day!

Gambar 17. Notifikasi email PenA

Pada gambar 17 merupakan informasi dari hasil yang sudah dilakukan pada generate Qrcode pulang oleh mahasiswa dan terlihat durasi bimbingan dalam 1 hari tersebut. Adanya integrasi dengan Rinfo sehingga memberikan informasi yang efektif dan akurat [24]. Pencapaian reward yang didapatkan terekam dengan baik dalam menu reward sehingga mahasiswa bimbingan lebih termotivasi dengan mahasiswa lainnya. Serta menjadi nilai tambah bagi dosen pembimbing atas kehadiran yang mahasiswa bimbingan.

\section{SIMPULAN}

Absensi yang dilakukan pada Perguruan Tinggi saat ini sudah baik yaitu menggunakan sistem website Penilaian Absensi (PenA) secara online. Dengan login SSO (Single Sign On) kemudian lakukan scanning QrCode, yang memudahkan mahasiswa bimbingan dalam absensi maupun melihat rekapan kehadiran. Diterapkannya gamifikasi pada website Penilaian Absensi (PenA) guna meningkatkan motivasi mahasiswa bimbingan agar lebih rajin lagi dalam kehadiran dan juga tidak monoton. Selain itu, mahasiswa bimbingan juga dapat lebih interaktif komunikasi dalam bimbingan kepada dosen pembimbing. Dengan adanya gamifikasi berupa reward untuk mahasiswa bimbingan yang sudah melebihi 10 jam kehadirannya bisa dijadikan point tambahan nilai bagi dosen pembimbing 
sehingga menimbulkan terpacunya mahasiswa untuk rajin dalam hadir bimbingan. Serta dari kehadiran pun bisa lebih menarik dan menyenangkan dengan adanya gamifikasi.

\section{DAFTAR PUSTAKA}

Rahardja, U., Harahap, E. P., \& Dewi, S. R. (2019). The Strategy of Enhancing Article Citation and H-Index on SINTA to Improve Tertiary Reputation.

TELKOMNIKA

(Telecommunication

Computing Electronics and Control), 17(1).

Rahardja, U., Aini, Q., \& Hardini, M. (2018). PENERAPAN SOFTWARE AKUNTANSI ONLINE SEBAGAI

PENUNJANG PENCATATAN

LAPORAN KEUANGAN.

SISFOTENIKA, 8(2), 176-187.

Rahardja, U., Harahap, E. P., \&

Pratiwi, S. (2018). Pemanfaatan

Mailchimp Sebagai Trend

Penyebaran Informasi

Pembayaran Bagi Mahasiswa

Di Perguruan Tinggi.

Technomedia Journal, 2(2), 3851.

Aini, Q., Graha, Y. I., \& Zuliana, S. R.

(2017). Penerapan Absensi

QRCode Mahasiswa Bimbingan

No. SK Akreditasi Ristekdikti : 34/E/KPT/2018
Belajar pada Website berbasis YII Framework. Sisfotenika, 7 (2), 207-218.

Aini, Q., Rahardja, U., \& Naufal, R. S. (2018). Penerapan Single Sign On dengan Google pada Website berbasis YII Framework. Sisfotenika, 8(1), 57-68.

Aini, Q., Rahardja, U., Madiistriyatno, H., \& Setiaji, Y. D. M. (2018). Pengamanan Pengelolaan Hak Akses Web Berbasis Yii Framework. Syntax Jurnal Informatika, 7(1), 52-63.

Pertiwi, D. H. (2011). Desain dan Implementasi Sistem Informasi Perpustakaan Berbasis WEB dengan MVC (Model View Controler). Jurnal Teknologi Informatika

(TEKNOMATIKA), 1

Aini, Q., Pratama, D., \& Heriyani, N. (2017).

PENERAPAN ZPRENEUR DENGAN TEHNIK GAMIFIKASI BERUPA TRANSFER ARMO UNTUK MENINGKATKAN KUALITAS

PEMBELAJARAN. CICES Journal, 3(1), 24-34.

Pramana, D., \& Damarayana, P. D. (2018).

IMPLEMENTASI 
GAMIFICATION PADA

APLIKASI UJIAN ONLINE

BERBASIS WEBSITE.

SEMNASTEKNOMEDIA

ONLINE, 6(1), 2-14.

Aini, Q., Rahardja, U., Moeins, A., \&

Apriani, D. M. (2018). Penerapan

Gamifikasi pada Sistem Informasi

Penilaian Ujian Mahasiswa Untuk

Meningkatkan Kinerja Dosen.

Jurnal Informatika Upgris, 4(1).

Ariessanti, H. D., \& Aini, Q. (2017).

Penerapan iDu iLearning Plus berbasis Gamification Sebagai Media Pembelajaran Jarak Jauh pada Perguruan Tinggi.

Technomedia Journal, 1(2), 3749.

Anwar, S., Marlena, N., \& Wulandari, R. (2018). EFEKTIFITAS GAMIFICATION BERBASIS BLENDED LEARNING PADA MATA KULIAH PENDIDIKAN EKONOMI. Jurnal Ekonomi Pendidikan dan Kewirausahaan, 6 (1), 5-14.

Supriyanto, S. (2017, August). Perancangan Penerapan

Gamifikasi pada Media Informasi Ekowisata. In Seminar Nasional Aplikasi Teknologi Informasi (SNATI).

Wastari, D. A. Y., \& Sagoro, E. M.
(2018). PENERAPAN MODEL PEMBELAJARAN

KOOPERATIF

BERBASIS

GAMIFIKASI

UNTUK

MENINGKATKAN HASIL

BELAJAR MATERI JURNAL

PENYESUAIAN PADA SISWA

KELAS X AKUNTANSI G SMK

MUHAMMADIYAH

TAHUN

AJARAN 2017/2018. Kajian

Pendidikan Akuntansi Indonesia, $7(8)$.

Rahardja, U., Handayani, I., \& Ningrum, A. A. (2018). Pemanfaatan Sistem iMe Berbasis WordPress sebagai Official Site RCEP pada Perguruan Tinggi. Creative Information Technology Journal, 4(3), 207-219.

Zuliana, S, R., 2017, IMPLEMENTASI

VIEWBOARD

PENA

(PENILAIAN

ABSENSI)

DENGAN

METODE

GAMIFIKASI

UNTUK

MENAMPILKAN AKTIVITAS

ABSENSI MAHASISWA

BIMBINGAN PADA

PERGURUAN TINGGI, Skripsi,

Program Studi Sistem Informasi, STMIK Raharja, Tangerang.

U. Rahardja, A. Moein, and N. 
Lutfiani, "Leadership,

Competency, Working

Motivation and Performance of High Private Education Lecturer with Institution Accreditation B: Area Kopertis IV Banten Province," Man India, vol. 97, no. 24, pp. 179-192

Adzan, M. A. N., Kusumaningrum, D. P., Rachmawanto, E. H., \& Sari, C. A. (2018). Integrasi Aplikasi Desktop dan Mobile pada Koperasi Karyawan Mitra Makmur. Jurnal Eksplora Informatika, 8(1), 42-51.

M. O. Sandonís, "Keeper: A tool for management and automated deployment of CMS web services,"in IEEE Nuclear Science Symposium and Medical Imaging Conference (2013 NSS/ MIC), Seoul, 2013.

Rahardja, U., Aini, Q., Azizah, N., \& Santoso, N. P. L. (2018). Efektivitas Akuntansi Online dalam Menunjang Proses Rekonsiliasi. Nusantara Journal of Computers and its Applications, 3(2).

Rahardja, U., Aini, Q., \& Khoirunisa, A. (2018). Monitoring Kinerja User Akuntan Menggunakan Dashboard Pada
Web Based Accounting Online di Perguruan Tinggi. SATIN-Sains dan Teknologi Informasi, 4(2), 58 -62 .

Maharani, S., Widagdo, P. P., \& Hatta, H. R. (2018). Rancang Bangun Sistem Informasi Praktek Kerja Lapangan (PKL) di Fakultas Ilmu Komputer dan Teknologi Informasi Universitas Mulawarman. Informatika Mulawarman: Jurnal Ilmiah Ilmu Komputer, 13(2), 71-75.

Rahardja, U., Aini, Q., Ariessanti, H. D., \& Khoirunisa, A. (2018). Pengaruh Gamifikasi pada iDu (iLearning Education) dalam Meningkatkan Motivasi Belajar Mahasiswa. Nusantara Journal of Computers and its Applications, 3 (2).

Rahardja, U., Aini, Q., \& Santoso, N. P. L. (2018). Pengintegrasian YII Framework Berbasis API pada Sistem Penilaian Absensi. SISFOTENIKA, 8(2), 140-152. 